\title{
Development of Randomly Amplified Polymorphic DNA-Sequence Characterized Amplified Region Marker for Identification of Apocynum venetum Linn. from $A$. pictum SCHRENK
}

\author{
Changmei Lu, ${ }^{*, a}$ Weiming Zhang,,${ }^{a, b}$ Xuemei Peng,,${ }^{a}$ Gongping Gu, ${ }^{a, b}$ Minmin Chen, ${ }^{a}$ and \\ Zezi $\mathrm{TANG}^{a}$ \\ ${ }^{a}$ Jiangsu Key Laboratory for Biodiversity and Biotechnology, College of Life Science, Nanjing Normal University; Nanjing \\ 210046, China: and ${ }^{b}$ Nanjing Institute for the Comprehensive Utilization of Wildplants; Nanjing 210042, China. \\ Received August 16, 2009; accepted December 2, 2009; published online December 7, 2009
}

\begin{abstract}
Apocynum venetum LinN. is an important Chinese crude drug, and its sibling species $A$. pictum SchrENK is a confusable herb which is similar to it. The purpose of this study is to develop DNA molecular markers to distinguish $A$. venetum from $A$. pictum through the combinative technologies of bulked segregate analysis (BSA) and randomly amplified polymorphic DNA (RAPD). Two putative markers B08-407 and B03-1368 specific for $A$. venetum were identified and sequenced. Based on the sequence information, two pairs of primers were designed and synthesized for sequence characterized amplified region (SCAR) markers. But only one primer pair, B031368, produced a clear SCAR band in all samples of $A$. venetum and not in $A$. pictum. This SCAR marker was found useful for rapid identification of $A$. venetum from $A$. pictum.
\end{abstract}

Key words Apocynum venetum; Apocynum pictum; identification; sequence characterized amplified region; randomly amplified polymorphic DNA; bulked segregate analysis

Apocynum venetum LinN. is a Chinese specific wild plant resource and belongs to Apocynum of Apocynaceae. A. venetum has been treated as medicine for more than a thousand years, the components such as flavanoid contained in its leaves have the effects of preventing and relieving high blood pressure, ${ }^{1,2)}$ hyperlipemia, ${ }^{3)}$ anxietas, ${ }^{4)}$ liver injury, ${ }^{5)}$ asthma and tracheitis ${ }^{6)}$ etc., which is recorded by "Chinese Pharmacopoeia". ${ }^{7)}$ A pictum SCHRENK has a similar appearance of $A$. venetum, ${ }^{8)}$ but is mainly applied in industries as fibres for spinning and papermaking etc. However, both $A$. venetum and $A$. pictum are known as "Luobuma" in Chinese people, and in recent years, $A$. venetum was in the verge of extinction for over-exploitation, only $A$. pictum has large areas of pure colonia. ${ }^{9)}$ It was common that $A$. venetum was replaced by $A$. pictum for medicinal, tea and tobacco use, which led to the confusion of the medicine and health products markets.

Former researchers have done some identification studies on the morphologic characteristics ${ }^{10)}$ and chemical compositions $^{11)}$ of the leaves of $A$. venetum and $A$. pictum. However, $A$. venetum distributes in a large area of about 14 provinces north of the Yangtze River east to the coast of the Yellow Sea and west to Xinjiang Uygur Autonomous Region, and A. pictum mainly grows on barren salt lick, dry river valley or Gobi desert in 3 provinces of Xinjiang, Gansu and Qinghai. The tremendous differences of the natural conditions, including the conditions of soil, water and atmosphere, lead to the great differences in appearance, structure and chemical compositions of leaves of $A$. venetum and $A$. pictum, especially $A$. venetum. $^{12,13)}$ In addition, the appearance, structure and chemical compositions of leaves were changing with the changes of growth stage ${ }^{13)}$ and the appearance and structure of the leaves were destroyed after the leaves being made into some goods, for instance the powdered goods (Table 2). The identification methods based on morphologic characteristics and chemical compositions were not workable. With the development of molecular biology and the innovation of related technologies, the identification of plants and medicinal sub- stances etc. on the DNA molecular level has become a feasible and widely used method. ${ }^{14)}$ The author had tried to use the DNA direct sequencing method to identify $A$. venetum from $A$. pictum, ${ }^{15)}$ but the sequencing cost was comparatively high and the sequencing time was comparatively long, which was adverse to rapid identification. While randomly amplified polymprphic DNA-sequence characterized amplified region (RAPD-SCAR) which was developed on the basis of RAPD had been successfully applied to the identification of medicinal plants such as Phyllanthus emblica ${ }^{14)}$ and Cenchrus ciliaris ${ }^{17)}$ etc.

In this paper, combined technologies of RAPD and bulked segregate analysis (BSA) were first used to amplify samples of $A$. venetum and $A$. pictum from different areas of China and to find the RAPD differential bands between $A$. venetum and $A$. pictum. Then the differential fragments were cloned and sequenced. According to the sequences, specific identification primers were designed and transformed into SCAR markers which could distinguish $A$. venetum from $A$. pictum quickly and exactly.

\section{MATERIALS AND METHODS}

Materials All the plant materials were collected by the Chinese Luobuma resource scientific investigation team from various regions of China in 2005 and the concrete information was shown in Table 1. Under natural conditions, A. venetum and $A$. Pictum reproduce themselves by asexual reproduction. In order to avoid collecting samples with the same genetic composition, the distances between different samples were at least $1 \mathrm{~km}$ or more. Leaves were dried by silica gel and identified by Xiao Zhengchun from Nanjing Institute of Comprehensive Utilization of Wild Plants. Voucher specimens (collection No. from 200535 to 2005109) were deposited at the herbarium of Nanjing Institute of Comprehensive Utilization of Wild Plants for further reference. Six Luobuma goods samples (collection No. from 2005110 to 
Table 1. Plant Materials

\begin{tabular}{|c|c|c|c|c|c|}
\hline Species & Sample codes & Origin/collector & Number of samples & Voucher number & Collection date \\
\hline \multirow[t]{10}{*}{ Apocynum venetum LinN. } & L1 & Altay, Xinjiang/Gu G. & 5 & $200545-200549$ & $2005-7-18$ \\
\hline & L2 & Korla, Xinjiang/Zhang W. & 5 & $200535-200539$ & $2005-7-14$ \\
\hline & L3 & Tongliaozha Qi, Inner Mongolia/Gong Z. & 5 & $200575-200579$ & $2005-8-15$ \\
\hline & L4 & Yumen, Gansu/Gong Z. & 5 & $200580-200584$ & $2005-8-30$ \\
\hline & L5 & Yinchuan, Ningxia/Xian X. & 5 & $200565-200569$ & $2005-8-5$ \\
\hline & L6 & Xingping, Shanxi/Qian X. & 5 & $200560-200564$ & $2005-7-27$ \\
\hline & L7 & Sanmenxia, Henan/Qian X. & 5 & $200595-200599$ & $2005-9-8$ \\
\hline & L8 & Dongtai, Jiangsu/Zhang W. & 5 & $2005105-2005109$ & $2005-9-15$ \\
\hline & L9 & Changling, Jilin/Gong Z. & 5 & $200570-200574$ & $2005-8-10$ \\
\hline & L10 & Xiaoxian, Anhui/Lu Z. & 5 & $2005100-2005104$ & 2005-9-12 \\
\hline \multirow[t]{5}{*}{ A. pictum $\mathrm{S}$ CHRENK } & B1 & Bachu, Xinjiang/Gu G. & 5 & $200550-200554$ & $2005-7-20$ \\
\hline & B2 & Korla, Xinjiang/Zhang W. & 5 & $200540-200544$ & $2005-7-14$ \\
\hline & B3 & Yumen, Gansu Gong Z. & 5 & $200585-200589$ & $2005-8-30$ \\
\hline & B4 & Dunhuang, Gansu/Gu G. & 5 & $200555-200559$ & $2005-7-26$ \\
\hline & B5 & Gomud, Qinghai/Gu G. & 5 & $200590-200594$ & $2005-9-2$ \\
\hline
\end{tabular}

All the materials were collected by the Chinese Luobuma resource scientific investigation team in 2005 and identified by Xiao Zhengchun.

Table 2. Luobuma Goods Samples

\begin{tabular}{|c|c|c|c|c|c|}
\hline No. & Trade name & Raw material/origin & Product character & Manufacturer & $\begin{array}{l}\text { Voucher } \\
\text { number }\end{array}$ \\
\hline 1 & "Luto" Apocynum tea & A. pictum/Xinjiang & Enveloped & Xinjiang Bachu County Apocynum Tea Plant & 2005110 \\
\hline 2 & "Big flower" Luobuma tea & A. pictum/Xinjiang & Enveloped & $\begin{array}{l}\text { Xinjiang Yuli Jiangbao Comprehensive Exploitation of } \\
\text { Luobuma Co., Ltd. }\end{array}$ & 2005111 \\
\hline 3 & "Tonghui" Luobuma tea & A. venetum/Xinjiang & Powder & Inner Mongolia Triumph Industrial Co., Ltd. & 2005112 \\
\hline 4 & "Jinran” Lobm tea & A. venetum/Shanxi & Crimple and curled & Shanxi Runhua Tea Co., Ltd. & 2005113 \\
\hline 5 & "Baisui" Luobuma tea & A. venetum/Xinjiang & Enveloped & Xinjiang Korla Alham Luobuma Plant & 2005114 \\
\hline 6 & "Niyaren" Luobuma tea & A. venetum/Xinjiang & Powder & Xinjiang Green Health Luobuma Co., Ltd. & 2005115 \\
\hline
\end{tabular}

All the goods samples were purchased by the Chinese Luobuma resource scientific investigation team in 2005 directly from the manufacturer and the identification of the raw materials was according to the combined information of packing indication, original place of raw materials and the fresh leaves in factories.

2005115) were purchased by the Chinese Luobuma resource scientific investigation team in 2005 directly from the manufacturer and the identification of the raw materials was according to the combined information of packing indication, original place of raw material and the fresh leaves in factories. Their concrete information was shown in Table 2.

DNA Isolation DNA was extracted with a Qiagen DNeasy Plant Mini Kit (Qiagen, Valencia, CA, U.S.A.). DNA extractions followed manufacturer's protocols with the modification of buffer AP1 lysis conditions by the addition of papain (Sigma) to the final concentration of $50 \mathrm{mg} / \mathrm{ml}$, and incubation at $37^{\circ} \mathrm{C}$ for $12 \mathrm{~h}$ on a rocking platform.

Construction of Gene Pool Two gene pools were constructed by the sample genome DNA of $A$. venetum from 10 regions and $A$. pictum from 5 regions, and the template DNA concentration of the two gene pools was $20 \mathrm{ng} / \mu \mathrm{l}$.

RAPD-Polymerase Chain Reaction (PCR) The PCR amplification was performed in a $25 \mu \mathrm{l}$ reaction system. A reaction tube contained $30 \mathrm{ng}$ of DNA, $1.5 \mathrm{U}$ of Taq DNA polymerase enzyme, 5 pmol of each deoxyribonucleotide triphosphate (dNTP), 1X Taq polymerase buffer with $2.5 \mathrm{~mm}$ of $\mathrm{MgCl}_{2}$, and $10 \mathrm{pmol}$ of each primer. The amplification was carried out in a DNA thermal cycler (Eppendorf, German) using following parameters: $94{ }^{\circ} \mathrm{C}$ for $5 \mathrm{~min} ; 42$ cycles at $94^{\circ} \mathrm{C}$ for $45 \mathrm{~s}, 36^{\circ} \mathrm{C}$ for $30 \mathrm{~s}$, and $72^{\circ} \mathrm{C}$ for $2 \mathrm{~min}$; and a final extension at $72^{\circ} \mathrm{C}$ for $7 \mathrm{~min}$. PCR products were subjected to agarose gel $(1.5 \%[\mathrm{w} / \mathrm{v}])$ electrophoresis in $0.5 \mathrm{X}$ TBE buffer, along with DNA ladders (Takara, Japan) as size markers. DNA was stained with ethidium bromide and photographed under UV light (GDS-8000, UVP, U.S.A.).

Screening Strategy and Identification of Specific RAPD Amplicon Eighty random primers (Table 3) (Shanghai Sangon, Inc., China) were screened by RAPD for identification of specific marker. Each amplification of DNA on two pools or samples from 10 populations of $A$. venetum and 5 populations of $A$. pictum was performed with a single primer. The amplicons, which only existed in all samples of $A$. venetum and not existed in samples of $A$. pictum were identified.

Cloning and Sequencing of Specific RAPD Fragments The specific RAPD fragments were purified with a 3 S Spin Agarose Gel DNA Purification Kit (Shanghai Shenergy Biocolor Inc., China), and cloned in pMD18-T vector (Takara, Japan). The plasmids harboring inserts of the expected size were extracted and sequenced partially at both ends using an automated sequencer (Prism 377, ABI, U.S.A.). The DNA sequences were submitted to GenBank (Accession numbers: ET030151 and ET030150).

Designing SCAR Primers and SCAR-PCR Two pairs of SCAR primers were designed from the sequence information of the specific RAPD fragments. They were used to amplify the two gene pools and the genome DNA of each sample of $A$. venetum and A. pictum. What contained in each reaction tube was similar to the above-mentioned. Thermal cycling conditions for the amplification were optimized as: $94^{\circ} \mathrm{C}$ for $3 \mathrm{~min} ; 29$ cycles at $94^{\circ} \mathrm{C}$ for $45 \mathrm{~s}, 59^{\circ} \mathrm{C}$ for $30 \mathrm{~s}$, and $72{ }^{\circ} \mathrm{C}$ for $90 \mathrm{~s}$; and a final extension at $72^{\circ} \mathrm{C}$ for $7 \mathrm{~min}$. PCR amplification for authentication of commercial samples was carried out using the SCAR primer pair with the above- 
Table 3. Names and Sequences of Random Primers

\begin{tabular}{|c|c|c|c|}
\hline Primer & Sequence $\left(5^{\prime} \rightarrow 3^{\prime}\right)$ & Primer & Sequence $\left(5^{\prime} \rightarrow 3^{\prime}\right)$ \\
\hline $\mathrm{A} 01 *$ & CAGGCCCTTC & $\mathrm{C} 01$ & TTCGAGCCAG \\
\hline $\mathrm{A} 02 *$ & TGCCGAGCTG & $\mathrm{C} 02 *$ & GTGAGGCGTC \\
\hline A03 & AGTCAGCCAC & $\mathrm{C} 03$ & GTGAGGCGTC \\
\hline A04 & AATCGGGCTG & $\mathrm{C} 04$ & ССGСАТСТАС \\
\hline A05 & AGGGGTCTTG & $\mathrm{C} 05$ & GATGACCGCC \\
\hline A06 & GGTCCCTGAC & $\mathrm{C} 06^{*}$ & GAACGGACTC \\
\hline A07 & GAAACGGGTG & $\mathrm{C} 07$ & GTCCCGACGA \\
\hline A08 & GTGACGTAGG & $\mathrm{C} 08^{*}$ & TGGACCGGTG \\
\hline $\mathrm{A} 09^{*}$ & GGGTAACGCC & $\mathrm{C} 09^{*}$ & CTCACCGTCC \\
\hline A10* & GTGATCGCAG & C10* & TGTCTGGGTG \\
\hline $\mathrm{A} 11 *$ & CAATCGCCGT & C11 & AAAGCTGCGG \\
\hline A12 & TCGGCGATAG & $\mathrm{C} 12 *$ & TGTCATCCCC \\
\hline A13 & CAGCACCCAC & $\mathrm{C} 13$ & AAGCCTCGTC \\
\hline $\mathrm{A} 14^{*}$ & TCTGTGCTGG & $\mathrm{C} 14$ & TGCGTGCTTG \\
\hline A15* & TTCCGAACCC & $\mathrm{C} 15^{*}$ & GACGGATCAG \\
\hline A16* & AGCCAGCGAA & $\mathrm{C} 16^{*}$ & САСАСТССАG \\
\hline $\mathrm{A} 17^{*}$ & GACCGCTTGT & $\mathrm{C} 17$ & TTCСССССАG \\
\hline A18* & AGGTGACCGT & $\mathrm{C} 18$ & TGAGTGGGTG \\
\hline A19 & CAAACGTCGG & C19 & GTTGCCAGCC \\
\hline A20 & GTTGCGATCC & $\mathrm{C} 20$ & АСTTCGCCAC \\
\hline $\mathrm{B} 01 *$ & GTTTCGCTCC & D01* & ACCGCGAAGG \\
\hline $\mathrm{B} 02 *$ & TGATCCCTGG & D02 & GGACCCAACC \\
\hline B03* & САТСССССТG & D03* & GTCGCCGTCA \\
\hline B04* & GGACTGGAGT & D04 & TCTGGTGAGG \\
\hline B05* & TGCGCCCTTC & D05 & TGAGCGGACA \\
\hline B06 & TGCTCTGCCC & D06 & ACCTGAACGG \\
\hline B07 & GGTGACGCAG & D07* & TTGGCACGGG \\
\hline B08* & GTCCACACGG & D08 & GTGTGCCCCA \\
\hline В09 & TGGGGGACTC & D09 & СTCTGGAGAC \\
\hline $\mathrm{B} 10^{*}$ & CTGCTGGGAC & D10 & GGTCTACACC \\
\hline $\mathrm{B} 11 *$ & GTAGACCCGT & D11 & AGCGCCATTG \\
\hline $\mathrm{B} 12 *$ & ССTTGACGCA & D12 & CACCGTATCC \\
\hline B13 & TTCCCCCGCT & D13 & GGGGTGACGA \\
\hline B14 & TCCGCTCTGG & D14 & СТТССССААG \\
\hline $\mathrm{B} 15^{*}$ & GGAGGGTGTT & D15 & СATCCGTGCT \\
\hline B16 & TTTGCCCGGA & D16* & AGGGCGTAAG \\
\hline B17 & AGGGAACGAG & D17 & TTTCCCACGG \\
\hline B18 & CCACAGCAGT & D18* & GAGAGCCAAC \\
\hline B19 & ACCCCCGAAG & D19* & CTGGGGACTT \\
\hline $\mathrm{B} 20$ & GGACССTTAC & D20 & ACCCGGTCAC \\
\hline
\end{tabular}

They were purchased from Shanghai Sangon, Inc. of China. The asterisk represents the primers which produced clear differential bands

mentioned thermal cycling conditions.

\section{RESULTS}

The gene pools of $A$. venetum and $A$. pictum were amplified and screened by 80 RAPD random primers. It was found that 34 random primers could generate clear differential bands between $A$. venetum and $A$. pictum (Table 3 ).

Then, the genome DNA of each $A$. venetum samples from 10 regions and each $A$. pictum samples from 5 regions were performed with RAPD-PCR amplification again by the selected 34 primers. Results showed that only primer B08 and B03 could generate clear and stable difference between all detected samples of $A$. venetum and A. pictum. Primer B08 could produce bands in all $A$. venetum samples near $450 \mathrm{bp}$, but not in any $A$. pictum sample. Because the RAPD pattern of different samples from the same region were very similar and the lane numbers in one electrophoresis blanket was limited, Fig. 1, together with Figs. 2 and 4, only showed the result from one randomly selected sample of every region. The band was recorded as B08-450 temporarily. Primer B03

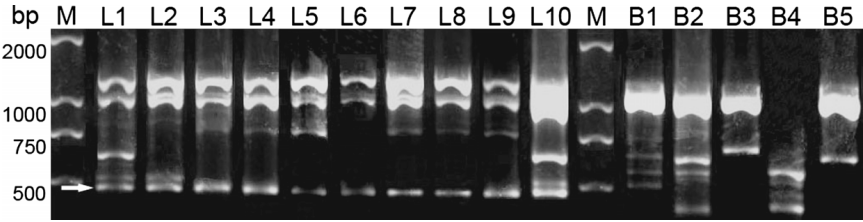

Fig. 1. RAPD Pattern Amplified with B08 Primer

M: DNA marker; L1-L10: samples of A. venetum; B1-B5: samples of A. pictum Their voucher numbers were 200545, 200538, 200576, 200583, 200566, 200563, 200597, 2005108, 200572, 2005103, 200552, 200542, 200588, 200557 and 200593, respectively. Their collection localities were showed in Table 1 . The white arrow showed the different bands between $A$. venetum and A. pictum.

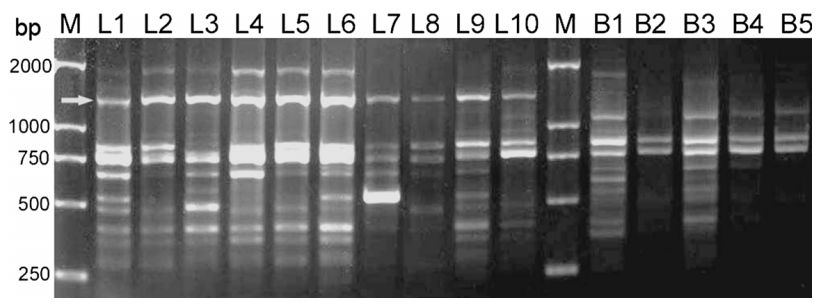

Fig. 2. RAPD Pattern Amplified with B03 Primer

M: DNA marker; L1-L10: samples of A. venetum; B1-B5: samples of A. pictum. Their voucher numbers were 200547, 200536, 200578, 200567, 200564, 200596, 2005106, 200574, 2005102, 200552, 200542, 200587, 200556 and 200593, respectively. Their collection localities were showed in Table 1 . The white arrow showed the different bands between $A$. venetum and A. pictum.

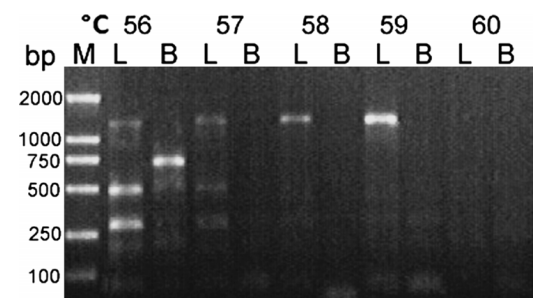

Fig. 3. Optimization of PCR Amplification on Pools of A. venetum (L) and $A$. pictum (B) with B03-1368 SCAR Primer

M: DNA marker; L: pool of A. venetum; B: pool of A. pictum. Annealing temperature ranging from 56 to $60^{\circ} \mathrm{C}$.

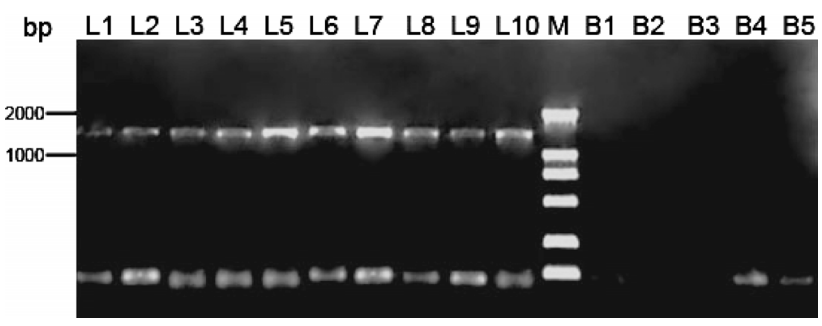

Fig. 4. PCR Pattern of A. venetum (L) and A. pictum (B) Obtained with B03-1368 SCAR Primer

L1-L10: samples of $A$. venetum; B1-B5: samples of $A$. pictum. Their voucher numbers were 200545, 200536, 200578, 200581, 200569, 200564, 200597, 2005106, 200574, 2005103, 200553, 200543, 200589, 200557 and 200592, respectively. Their collection localities were shown in Table 1.

could produce bands in all $A$. venetum samples near $1500 \mathrm{bp}$, but not in any $A$. pictum sample (Fig. 2). The band was recorded as B03-1500 temporarily. B08-450 and B03-1500 were selected as the putative specific markers for $A$. venetum.

Full-length sequences of the two fragments were obtained by the cloning and sequencing of B08-450 and B03-1500, and the primal 10 base of the two sequences were exactly the 
Table 4. Designed SCAR Primer Pairs and Sizes of SCAR-PCR Products

\begin{tabular}{|c|c|c|c|}
\hline RAPD marker & GenBank accession number & SCAR primer sequence $\left(5^{\prime} \rightarrow 3^{\prime}\right) /$ size $/ b p$ & Size of SCAR marker/bp \\
\hline B08-407 & ET030151 & F-gtccacacggcaggag/16 R-gtccacacggggttcc/16 & 407 \\
\hline B03-1368 & ET030150 & F-catcccctgcccc/14 R-catcccctgagtccag/17 & 1368 \\
\hline
\end{tabular}

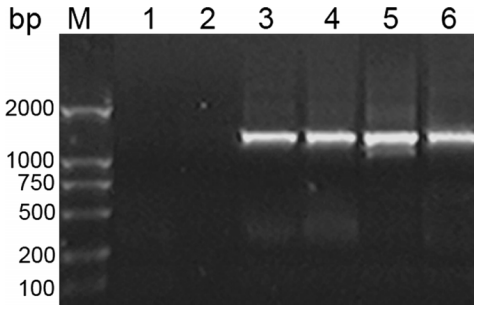

Fig. 5. PCR Amplification of Genomic DNA from 6 Commercial Samples of A. venetum and A. pictum with B03-1368 SCAR Primer

M: DNA marker; 1, 2: A. pictum; 3-6: A. venetum. Their concrete information was shown in Table 2.

same as the corresponding RAPD primer B08 and B03. Their GenBank accession numbers were ET030151 and ET030150, and their actual measured lengths were $407 \mathrm{bp}$ and $1368 \mathrm{bp}$, respectively. So, B08-450 and B03-1500 were renamed as B08-407 and B03-1368.

According to the both ends sequences of segment B08-407 and B03-1368, two pairs of SCAR primers B08-407F/R and B03-1368F/R (Table 4) were designed and synthesized. Using the gene pools of $A$. venetum and $A$. pictum as templates, the identification feasibility of the two pairs of primers was detected with the reannealing temperature ranging from 50 to $60{ }^{\circ} \mathrm{C}$. The amplification conditions were optimized simultaneously. When the B08-407 SCAR primer pairs were detected, both gene pools produced clear bands near $400 \mathrm{bp}$ when the reannealing temperature ranging from 50 to $57^{\circ} \mathrm{C}$, but both produced no band when the temperature over $58^{\circ} \mathrm{C}$. When B03-1368 SCAR primer pairs were detected, the gene pool of $A$. venetum produced obvious band near the corresponding location of $1368 \mathrm{p}$ with the reannealing temperature ranging from 56 to $59^{\circ} \mathrm{C}$, and at $59{ }^{\circ} \mathrm{C}$, the band was the most clear and no mixed band existed, while the gene pool of $A$. pictum produced no band within the above temperature range (Fig. 3). Therefore, B08-407 SCAR primer was invalid, and the best reannealing temperature for B03-1368 SCAR primer was $59^{\circ} \mathrm{C}$.

Each genome DNA of all detected samples of $A$. venetum and $A$. pictum was amplified under optimized conditions by the B03-1368 SCAR primer pair. The results showed that all $A$. venetum samples had a clear and bright band at $1368 \mathrm{bp}$, while all $A$. pictum samples had no amplified band at that site (Fig. 4).

The genome DNA of 6 commercial samples of $A$. venetum and $A$. pictum were amplified with B03-1368 SCAR primer pair further. Four $A$. venetum samples could repeatedly amplify clear bands near $1368 \mathrm{bp}$, while $2 \mathrm{~A}$. pictum samples had no clear band (Fig. 5).

\section{DISCUSSION}

A. venetum and A. pictum are two different species of Apocynum distributed in China. There is no definite differ- ence between the leaves of the two plants, and the morphosis of leaves is also different in different growth stages and different environments. ${ }^{13)}$ What's more, the morphosis of the leaves is destroyed when the leaves are processed into products. Therefore, the identification of $A$. venetum and $A$. pictum is always a problem that people hope to solve. $A$. venetum and $A$. pictum could be accurately identified by the direct determination and comparison of the sequences in the $\operatorname{trn} \mathrm{L}$ intron and trnL-F non-coding region, ${ }^{15)}$ but the cost is comparatively high and the sequencing time is too long, which is adverse to rapid identification. Restriction enzyme recognition sites in the two regions from $A$. venetum and $A$. pictum are exactly the same, and PCR-RFLP method cannot be used to distinguish them. Furthermore, we have tried to design specific primers in accordance with the sequence differences of these two regions between them. But too narrow range of annealing temperature means little practical application. ${ }^{15}$ )

RAPD analysis can reveal high degree of polymorphism which does not require prior DNA sequence information of the species and is easy to perform. Various researchers have explored its application for authentication of traditional medicines Phyllanthus emblica, ${ }^{14)}$ Cenchrus ciliaris ${ }^{17)}$ etc.

The combination of BSA and RAPD methods is usually used to find the molecular markers which are linked to target gene. ${ }^{18)}$ In order to facilitate the screening of primers, methods of BSA and RAPD were combined and the intraspecies genetic differences of different regions and different individuals were ignored in this study. Thirty-four primers which could produced obvious difference between two gene pools were picked out from 80 random primers quickly. This saved much time for preliminary screening of primers. Then, the selected 34 primers were used to amplify the samples from different regions of China, and only two primers B03 and B08 could generate clear and different bands between all detected samples of $A$. venetum and $A$. pictum.

Because RAPD random primer has a length of only $10 \mathrm{bp}$, the reproducibility of RAPD reaction is not so good and the analysis is relatively complex. ${ }^{19)}$ But in SCAR, the primers are completely complementary with the nucleotide sequence of the species waiting for identification and the extended primers could amplify specific genome fragment under strict conditions, which make SCAR markers more specific and reliable than RAPD markers ${ }^{20)}$ (Fig. 3). Two pairs of SCAR primers were designed according to the sequences of fragments B08-407 and B03-1368, but only B03-1368 SCAR primer could amplify the band with corresponding length in all natural and commercial $A$. venetum samples, while no such band could be amplified in all $A$. pictum samples (Figs. 4, 5). Therefore, through this study, we have developed a RAPD-SCAR marker for identification of $A$. venetum from A. pictum.

$A$. venetum is widely distributed in large areas of China. $A$. venetum from different regions has a certain difference in phenotypes and curative effects. How to find out the $A$. vene- 
tum resource with high quality from so many types of $A$. venetum and to develop the molecular markers is our ongoing work.

Acknowledgements Thanks for the financial assistance of Chinese "Tenth Five-Year" National Science and Technology Research Fund (2004 BA502B10) and High-tech Research Projects of Jiangsu Province (BG2006318).

\section{REFERENCES}

1) Kamata K., Seo S., Nakajima J., Nat. Med. (Tokyo), 62, 160-163 (2008).

2) Kim D. W., Yokozawa T., Hattori M., Kadota S., Namba T., J. Ethnopharmacol., 72, 53-59 (2000).

3) Kim D. W., Yokozawa T., Hattori M., Kadota S., Namba T., Phytother. Res., 12, 46-48(1998).

4) Grundmann O., Nakajima J. I., Seo S., Butterweck V., J. Ethnopharmacol., 110, 406-411 (2007).

5) Xiong Q., Fan W., Tezuka Y., Adnyana I. K., Stampoulis P., Hattori M., Namba T., Kadota S., Planta Med., 66, 127-133 (2000).

6) Wei J. M., J. Tradit. Chin. Med., 8, 34-36 (1988).

7) Chinese Pharmacopoeia Commission, "Chinese Pharmacopoeia," Chemical Industry Press, Beijing, 2005, p. 147.
8) Lv H. J., Huang J. P., Lu J., Zhang Y. F., Li J. B., Journal of Guangxi Traditional Chinese Medical University, 11, 44-46 (2008).

9) Zhang W. M., Xiao Z. C., Gu G. P., Zhang G. L., Qian X. S., Chinese Wild Plant Resources, 25, 15-19 (2006).

10) Chen X. M., Li B. T., Guihaia, 11, 146-148 (1991).

11) Nishibe S., Murai M., Chinen C., Kawamura T., Noro Y., Nat. Med., 148, 322-323 (1994).

12) Jiang Y., Li B., "Flora of China," Vol. 63, Science Press, Beijing, 1977, pp. $157-161$.

13) Han L. W., Hou J. J., Li Y. L., Liang T. G., Li Q. S., Chinese Journal of Modern Applied Pharmacy, 23, 392-394 (2006).

14) Michelmore R. W., Paran I., Kesseli R. V., Proc. Natl. Acad. Sci. U.S.A., 66, 9828—9832 (1991).

15) Peng X. M., Zhang W. M., Wang M. L., Lu C. M., Gu G. P., Bulletin of Botanical Research, 27, 2-5 (2007).

16) Dnyaneshwar W., Preeti C., Kalpana J., Bhushan P., Biol. Pharm. Bull. 29, 2313-2316 (2006).

17) Dwivedi K. K., Bhat S. R., Bhat V., Bhat B. V., Gupta M. G., Plant Sci., 172, 788-795 (2007).

18) Liu S. X., Griffey C. A., Maroof M. A. S., Crop Sci., 41, 1268-1275 (2001).

19) Valentini A., Timperio A. M., Cappuccio I., Zolla L., Electrophoresis, 17, 1553-1554 (2005).

20) Choi Y. E., Ahn C. H., Kim B. B., Yoon E. S., Biol. Pharm. Bull., 31, $135-138$ (2008). 